\title{
Milligram Per Gram of Creatinine
}

National Cancer Institute

\section{Source}

National Cancer Institute. Milligram Per Gram of Creatinine. NCI Thesaurus. Code C105502.

A unit of substance concentration defined as the number of milligrams per gram of creatinine. 